\title{
Design Concept and Model of Pedagogical System of University Teachers' Training for Tutors Activities
}

\author{
${ }^{1}$ Glukhov Gennady Vasilyevich, ${ }^{* 2}$ Gromova Tatiana Vladimirovna, ${ }^{3}$ Nikitina Irina Nikolaevna \\ ${ }^{1, * 2}$ Doctor of Pedagogical Sciences, Professor of Samara State University of Economics, Samara, Russian \\ Federation, ${ }^{3}$ Candidate of Philological Sciences, Assistant Professor of Samara State University of Economics, \\ Samara, Russian Federation \\ Email: glukhov.g@mail.ru;"gromova73@yandex.ru; i.n.nikitina@gmail.com
}

Received: $09^{\text {th }}$ February 2018, Accepted: $14^{\text {th }}$ February 2018, Published: 28th February 2018

\begin{abstract}
The article is devoted to designing a model of pedagogical system of training University teachers for tutors activities (tutors - here: teachers in the distance learning system). Currently, few universities can offer much in the training of distance learning teachers /tutors. Insufficient number of tutors and /or their unsatisfactory readiness (professional, psychological, technical) seem to be the main obstacle in the use of distance learning (DL) in universities. The organization of special tutors training is considered possible solution to the problem and a resource for improving the quality of professional education. The article reflects the following aspects: the basic provisions of the design concept of pedagogical system of teachers training for tutors' activities are justified; the model of pedagogical system of training university teachers for tutoring activities is presented; general characteristics of structural components of pedagogical system of teachers training in DL system (goal, content, means of pedagogical communication, trainers, trainees) are introduced. The obtained results can be used in DL teachers training in educational institutions of different profile
\end{abstract}

Keywords: Informatization of Education, Distance Learning, Distance Education, Distance Learning Teacher, Distance Learning System, Information and Telecommunication Technologies, Tutor

\section{Introduction \\ Establishing a context}

Despite the technical equipment of many universities high potential of distance and information technology is not being used fully due to the lack or insufficient readiness of universities teachers to fulfill activities in DL system (DLS). The challenge is therefore to prepare the staff. We believe that the system of training of high school teachers to work in the field of distance education will improve the quality of their professional skills and broaden the scope of educational activities in case:

- its development and implementation is conducted on the basis of the analysis of the distance training and the identification of scientific and practical prerequisites of pedagogical system model of training of high school teachers to students distance learning;

- The components of the designed theoretical model of pedagogical system of teachers training (goal, content, and means of pedagogical communication, trainers, and trainees) are determined by the requirements of acceleration of socio-economic development of the country and modern pedagogical and information and communication technologies.

\section{Literature Review}

The problems of distance learning and DL teachers training have been the subject of study of such researchers as Alvarez et al. (2009) [1], Benque (1999) [2], Borisova \& Kuzov (2000) [3], Kazanskaya \& Nikitina (2001) [4], Liyanagunawar dena et al. (2014) [5], Virgil \& Varvel (2007) [6] and many others. In distance learning, like traditional learning, the main component responsible for the performance and quality of the educational process is the teacher. In distance education there appears a teacher of a new type that accompanies the student in DLS, and owns (in addition to his/her academic subject) a set of special techniques and methods, especially computer literacy (Borisova \& Kuzov, 2000) [3].

In foreign and Russian literature the teacher in DLS is called "a tutor". The introduction of the word "tutor" is connected with the peculiarities of the educational process in DL, the specifics of activities and division of labor of the teacher (Akhmatova \& Gurje, 2011 [7]; Benque, 1999 [2]; Khursheed, 2001 [8]; Rowland, 2000 [9]). In DL the tutor helps the students to build an individual trajectory of distance education. In the broader sense "a tutor" is a teacher, curator of the student, aiding him in organizing his education in any form of study (internal, correspondence, remote, external) (Moiseyeva, 2001) [10].

\section{Establishing a Research Gap}

Despite the theoretical and practical significance of these studies, their importance in solving the problems of raising the quality of education through the use of information and communication technologies, it should be noted that until now the design and implementation of scientifically based 
pedagogical system of teachers training for work in DLS is one of unexplored problems of theory and methods of professional education. In particular the technology of teachers training for DLS activity isn't presented in researches devoted to DL problems.

\section{Stating the Purpose}

The aim of the paper is to improve the professional qualification of university teachers in the field of information technology by theoretical study, design and implementation of educational training system for their work in DLS.

The necessity of the design model of pedagogical system of training of University teachers for tutor activity is driven by the strategic goals and objectives of modernization of education, the continuity of education throughout a person's life; the development of distance learning; creation of programs that implement information technology in education.

Distance learning is the education in which all or most of the training procedures are carried out with the use of modern information and telecommunication technologies in territorial separation of the teacher and students.

Analysis of the DL state at the present stage shows that the main element in the chain of tasks set by society is to train teachers for work in the DLS, because the main reason for insufficient use of the high potential of information and communication technologies in education is personnel component, i.e., the absence or lack of readiness (professional, technical, psychological) of University teachers for work in the DLS.

\section{Methods}

The solution of widespread DL usage in education depends on the solving the problems of DL teachers training. The problem is complex and multifaceted and involves a number of tasks such as: identification of psycho-pedagogical and theoretical and methodological bases of the system of training; justification the concept of designing technologies for DL teachers training; identifying the specific activities and the development of a multidimensional characteristics of the teacher as a subject of educational process; development of the contents of this training and creating a methodological complex for the effective implementation of this content in the format of educational and methodical manuals and recommendations, and programs; development and testing of technology of DL teachers training for work in DLS; identification of criteria of readiness of teachers to work in DL, its experimental verification. To solve the tasks we used the following research methods: theoretical - study of the psychological, scientific-pedagogical and methodological literature on the problem of DL teachers training, as well as domestic and foreign experience; design and analysis; empirical observation and questioning of participants of the educational process; as well as diagnostic, formative experiment, statistical processing of its results. These and other aspects are considered in the work (Gromova, 2011) [11].

This article will focus on the justification of the concept of designing a model of pedagogical system of high school teachers training for the work in DLS, presenting a theoretical model and description of the structural components of the educational system for training high school teachers for DL activities.

\section{Results}

1. Basic provisions that underpin the concept of designing the model of pedagogical system of tutors training

Before to develop a model of pedagogical system of training teachers for work in distance education, it should be theoretically justified. Let's consider the basic provisions that underpin the concept of designing the model of pedagogical system of tutors training.

\subsection{The first conceptual provision of pedagogical system of tutors training \\ It is known that the efficiency of the education system largely depends on how fully and comprehensively it will reflect (in the content, means, methods and organizational forms) those requirements imposed to it by social and economic development of society and pedagogical science, will take into account the perspective and the trends in their growth, will execute the social order of the society.}

This dependence is an objective reflection of a systematic approach to the organization of education, which acts as the first conceptual provision of the design model of pedagogical system of tutors training. From the standpoint of a systematic approach pedagogical system is considered a set of interrelated and interacting elements (purpose, principles of didactics, content, forms, methods, learning means, feedback, learning outcomes, subjects of the educational process, a system factor) intended to achieve educational goals with predictable results through joint activity of teacher and students. Therefore, a systematic approach involves the conversion of all of the structural elements of the pedagogical system with the introduction of any changes in one of them in accordance with the requirements of the social order and scientific and technological development (Kustov \& Gusev, 2006) [12]. 


\subsection{The second conceptual provision of pedagogical system of tutors training}

The modern society considered as information society and society of knowledge imposes new requirements to higher education. The disadvantages of existing education include the following: failure to provide all persons interested an opportunity to obtain affordable and high-quality education. The disadvantages of existing education include the following: failure to provide all persons interested an opportunity to obtain affordable and high-quality education; the backlog of acquired knowledge from the level of development of information and technology; low adaptability of education systems to the rapidly changing socio-economic conditions. In this regard, the second conceptual provision is the matching of the projected model of pedagogical system of tutors training to the requirements of accelerating of socio-economic development of society and modern pedagogical and informationcommunication technologies.

\subsection{The third conceptual provision of pedagogical system of tutors training \\ The third conceptual provision of the design model of the system is the choice of the principle of professional expediency as a backbone element. Under the backbone element, following (Bezrukova, 1990) [13], we understand the core idea and its concentrated expression, which runs through all elements of the pedagogical system and defines the methodology and the nature of learning technologies to achieve the integrated goals.}

The principle of professional advisability is the requirement, the implementation of which contributes to the achievement of the objectives of vocational education for the training of specialists. This principle allows us to vary the content of the training, its focus, methods and forms.

Rules for the implementation of the principle of professional advisability, according to V. S. Bezrukova (1990) [13] are as follows:

1) To make a selection of content, methods, means and forms of training taking into account peculiarities of specialty and assistance in mastering it;

2) To form professional qualities of students, facilitating career development and execution of professional duties;

3) To expand knowledge about professional activities and direct training of professionally and socially mobile professionals;

4) To use training to ensure continuous development and formation of personality.

The principle of professional advisability implies the need for continuous professional development and improvement of the higher education teacher in service training and the possible diversification of its activities.

1.4. The fourth conceptual provision of pedagogical system of tutors training Designing the model of pedagogical system of University teachers training for tutors activities is based on the gradual formation in the learning process of their professional skills. This is the fourth conceptual provision of the design model of the system of tutors training. Phasing involves strict adherence to the training stages one after another, without skipping any stages and violation of order, and following their patterns. In the context of the problems of research in developing the technology of teacher training and tutoring activities there is a gradual complication of their activities, starting with the ability to motivate students to development, to create and maintain a positive emotional background (motivational phase). The next step is mastering the theoretical foundations of teacher's activity in the system and the development of skills of independent work and independent information search; development of written communication (information phase, followed by the development of skills to use active learning methods, to install communication theoretical principles of the course with practical problems, to resolve conflicts (organizational and structural phase), and finally, developing the ability to think critically, possessing communication technology, improving skills to use available knowledge to solve non-standard problems (constructive phase), ending with the development of integrative skills of tutor activity, the ability of self-development and self-improvement, methods of self-analysis (reflective phase).

\subsection{The fifth conceptual provision of pedagogical system of tutors training}

The fifth conceptual provision is that the adequate to the requirements of educational practice in the training of University teachers should be on the basis of the provisions of the personal-oriented, andragogical (the necessity of taking into account professional and life experience, the presence of certain psychological barriers), activity and contextual approaches.

These approaches are largely linked to the humanization of education, which is seen as a development of educational systems acknowledging the personality of the teacher and students, harmonization of their interests, relationships and conditions for their development and selfdevelopment as one of the priority values.

In a narrower sense humanization is related to the increased inner strength and creative abilities of students, providing them intellectual freedom. Where there is such a focus on the educational 
activities of teachers, there exist faith in developing the abilities of the younger generation, an atmosphere of respect, kindness, cooperation; in such circumstances students feel more confident and, ultimately, become the subject of their own education, personal development, and active socialization.

1.6. The sixth conceptual provision of pedagogical system of tutors training

The sixth conceptual provision of designing the model of pedagogical system is that training of tutors should be based on the multidimensional representation of the tutor as the subject of the educational process, formed on the basis of functional-role-playing and personal activity models, the implementation of which ensures the formation of a complete personal and professional competence of a tutor (for more details see Gromova, 2011) [11].

\section{The model of pedagogical system of tutors} training

On the bases of the proposed conceptual provisions there was designed the model of pedagogical system of tutors' training, in which the characteristic of the basic structural components (goal, content, learning technologies, activities of the teacher and students) is given in accordance with the requirements of the backbone element (training of teachers for tutor activities) and system-forming factor (Fig. 1).
The logic of model development is as follows.

New socio-economic conditions have put before the society the task to the education system not only to provide a modern specialist with knowledge and skills, but also to form his core competencies, professional stability and the ability for professional self-determination in the context of rapidly changing technological conditions and the labor market. The society formulates the corresponding order for the education system. In new social conditions it is the social order for the specialist who possesses professional self-determination, who is in harmony with his private interests and future professional needs. The personal qualities of the specialist required by the society (among which the important place is taken by formation of professional stability and creative self-development) are set by a professional educational institution.

As was noted earlier, in the designing of pedagogical system of tutors training the principle of professional advisability was selected as a backbone factor. This principle allows selecting the content, methods, means and forms of training taking into account features of mastering the specialty and helping it, to shape professionally important qualities of students, facilitating the profession development and the performance of professional functions. 


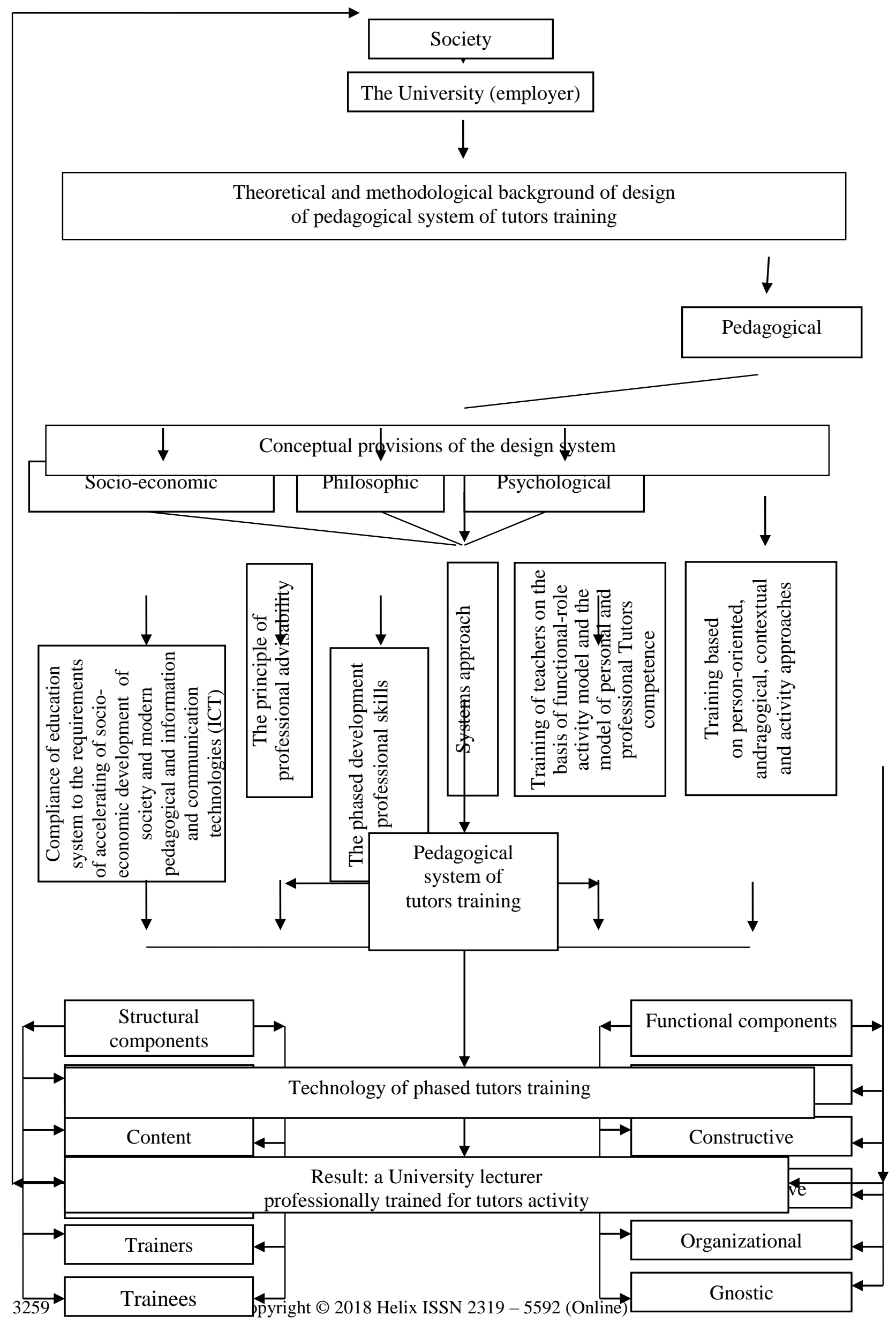




\section{Figure 1. The Model of Pedagogical System of Tutors Training}

Source: Gromova, T. (2011) [11]. Theory and technology of teachers preparation for work in distance learning (Doctoral dissertation). Tolyatti State University, Tolyatti, Samarskaya region, RF, $383 \mathrm{p}$.

The principle of professional advisability runs through all the elements of the model of the designed system and determines the method and character of learning technologies to achieve integrated goals. The goal, content, means of pedagogical communication, trainers and students must meet the requirements of the principle of professional advisability.

In accordance with the requirements of the system approach any change in the content, form, action of any leading component of an educational system should be accompanied by adequate restructuring of all its components.

Let's briefly review the features of the structural elements of the model of pedagogical system of tutors training.

\subsection{The goal of pedagogical system of tutors training}

The goal of learning. Designing the model of pedagogical system as any human activity begins with identifying goals. The exact purpose of education is the main task that needs to be solved because the organization of learning process is impossible without a clear idea of what we want to get as a result of training. The goal is a mental anticipation of the desired results and actions are directed at the achievement of it (Belousov \& Gromova, 2011) [14].

A new strategic element - training of teachers for the implementation of DL activities - was introduced in the aim of the pedagogical system of training teachers. Qualification characteristics of a DL teacher are "the goal setter" of the system of training. The main goal of the course is therefore to prepare University teachers for effective professional activity in DLS. It involves the acquisition of knowledge and skills allowing DL teachers to work effectively in DLS.

Taking into account the features of distance learning which is based on the use of modern information and communication technologies, the course examines psychological, didactic and organizational bases of distance learning and promotes the ability of trainees to develop learning materials and to use the technology of distance learning in the context of particular educational institution and specific discipline.

\subsection{The learning content of tutors training}

The learning content is the composition, structure and material of educational information, as well as complex tasks, assignments and exercises that form the professional skills of students, contribute to the accumulation of professional experience.

Learning process, methods and organizational forms of its realization are determined by its content, the selection of which shall be carried out strictly in accordance with the principle of professional advisability that is taking peculiarities of professional activity in DLS into account and helping to master it. Thus the use of DL technologies in the educational institution provides students, teachers and educational support personnel with educational-methodical complexes (EMC) (in paper or electronic form) to ensure the development and implementation of educational programs. The EMC includes: curriculum of the educational institution, the curriculum of the student, the academic subject (discipline, training courses), textbook academic subject (discipline, training courses), practicum or practical Handbook, test materials for quality control of learning material, guidelines for the student for the study of academic subject (discipline, training courses), organization of self-control, current control, educational (didactic) materials and problem books.

The EMC can be supplemented by an educational institution reference works and dictionaries, periodicals, industrial and socio-political publications, academic literature, readers, links to databases, websites, help systems.

(In the pedagogical system of Tutors training the learning content as part of educational information includes: e-learning (the essence, the main psychological and pedagogical principles and DL techniques; the tutor in DL (functions and competence of the tutor); forms of organization of educational-cognitive activity in DL, especially the interaction of the tutor and students in DL, the instructional materials in DL; control means in DL.

\subsection{Means of pedagogical communication in tutors training}

Means of pedagogical communication include methods, means and forms of education that enable the formation of professionally important qualities of students, facilitating the profession development and the performance of professional functions.

Selection of methods, means and forms of training future DL teachers should be guided by a set of requirements of a DL teacher (professional, computer literacy, ability to use various forms of organization of educational process, the ability to control, aspiration to self-development and selfimprovement; the ability to innovate, critical thinking, etc.) and professionally significant personal qualities of the DL teacher submitted in a model of his personal and professional competence. 
Distance learning includes five general didactic teaching methods: information-receptive, reproductive, problematic, heuristic and research (Lerner, 1981 [15]; Lewis et al., 2016 [16]). It is obvious that in educational process it is expedient to use a reasonable combination of traditional and innovative teaching methods. However, the system considered the most effective problem-research methods because they allow us to move from reproductive technologies to progressive creative, stimulating self-development and personal growth of students. They include so-called active teaching methods: business games, case study, brain storm method, immersion method, portfolio method, etc.

In the educational DL process more often than in traditional one they use innovative training tools based on the use of computer technology and telecommunications, as well as the latest achievements in the field of educational technology. Such well-known methods of training, as lectures, seminars, laboratory classes, examinations, course work, tests, exams, consultations, independent work, etc. take place in DL. However, in accordance with the model of learning and the DL technology they have their specificity both in contact and noncontact training periods. The special DL forms of educational-cognitive activity include: presentation of the course, tutorial, mutual aid group, Sunday school.

\subsection{The trainees (students) of the pedagogical system of tutors training}

In tutors training it is especially important to take into account the specifics of the learning process, which means that the students here are not just students but University lecturers and professors, people with a high level of development, with considerable practical experience, many of whom have academic degrees and titles. Experience shows that the students of the course "Teacher of distance learning system" demonstrate greater persistence, motivation, self-discipline and ability to work individually and have skills to work with computer and telecommunication means of communication than ordinary students. Professional training and retraining, expanding the scope of knowledge about professional activity promotes professional and personal growth, as well as the process of formation of professional and social mobility of University teachers that can solve current and future problems of education.

\subsection{The trainers (teachers) of the pedagogical system of tutors training}

It is known that the teacher is the most important component of the pedagogical system to ensure the effectiveness of the educational process. University teachers who have completed courses of tutors training (for example on the program "Tutor in distance education" at the Institute for information technologies in education of UNESCO) and have been certified can act as trainers. In future, teachers who have successfully completed training courses at the place of their work or advanced training in wellknown DL centers can be trainers.

The teacher is the main link in ensuring the high efficiency of educational process. The teacher should know and consider the peculiarities of personality-oriented, andragogical (taking into account professional and life experience, the presence of certain psychological barriers), contextual and activity approaches in the teaching process. These approaches are largely associated with the activation of inner strength and creative abilities of students, providing them with intellectual freedom, creating an atmosphere of mutual respect, goodwill and cooperation. Under such circumstances, the students feel more confident and, ultimately, become the subject of their own education, upbringing and personal development.

The end result of the implementation of the designed model of pedagogical system is teachers who are professionally prepared for work in DLS (Gluhov \& Gromova, 2016) [17].

Summarizing the abovementioned, we should note that the preparation of teachers to use modern information and communication technologies in the pedagogical process may contribute to the modernization of the education system in terms of changes technologies, methods, and nature of the activities of teachers and students, increasing its competitiveness on the educational market.

\section{Discussion}

As has been noted earlier, an essential element in ensuring the effectiveness of the educational process is the teacher for whom the term "tutor" was introduced. Organization of teachers/ tutors activity in the DLS was covered in the works of Russian and foreign researchers. Their works partly reflected the technology of teachers' activity in DLS (Atayan, 2001 [18]; Khursheed, 2001 [8]), the coordinating function of the teacher in DLS (Gavrilova \& Sergeyeva, 2001 [19]; Moiseyeva, 2001 [10], specific activities and specific requirements for DL teachers (Liyanagunawardena et al., 2014 [5]; Tuninga, 1995 [20]; Virgil \& Varvel, 2007 [6]), teacher training in the field of new pedagogical technologies (Kazanskaya \& Nikitina, 2001 [4]; Alvarez, Guasch \& Espasa, 2009 [1]), the system of management of educational services using distance technologies (Kraineva, 2009 [21]; Khutorskoy, $2001[22])$.

But despite the theoretical and practical significance of these studies in the task of improving the quality of education problems through the use of information and communication technologies it should be noted that so far development and 
implementation of scientifically grounded system of preparation of teachers to work in DLS is one of the poorly explored problems of theory and methodology of professional education.

Without pretending to a comprehensive solution, we believe, however, that this article could help to solve problems of training of University teachers to work in distance learning system.

Theoretical propositions, results and conclusions are of practical importance and can be used in the activities of universities and other institutions of professional and supplementary education.

The complexity of teachers work in new learning environment implies the need to develop principles and criteria associated with financial compensation for such activity, which may be the subject of further research

\section{Conclusion}

In conclusion, it should be noted that at the result of the work the following aspects were reflected: basic principles of designing of pedagogical system of teachers' training for tutors activities, the model of pedagogical system of tutors training; general characteristics of the structural components of pedagogical activity of teachers training system in DL (goal, content, means of pedagogical communication, teachers, students).

The continuation of further studies of this problem lies in the development of technology and testing of models of joint activities of students and teachers in DLS developing the model of personal and professional competence of the DL teacher aimed at the creation of professionally significant qualities of the DL teacher and developing technologies for the preparation of teachers to work in DLS.

The materials can be used in various kinds of teachers training courses and by the teachers who want to work in DLS in educational institutions of different profile (for more information see Gromova, 2011 [11]).

\section{Acknowledgements}

The authors express their gratitude to all those participated in this study for their kind cooperation, including Samara State University of Economics for the opportunity to conduct research and to publish the results in the form of this article

\section{References}

1- Alvarez, I., Guasch, T. \& Espasa, A. (2009). University teacher roles and competencies in online learning environments: A theoretical analysis of teaching and learning practices. European Journal of TeacherEducation, Vol. 32 (3), pp. 321-336.
2- Benque, N. (1999). Online training for Tutors. Proceedings of Online Education. Berlin: Springer Verlag, $208 \mathrm{p}$

3- Borisova, N. V. \& Kuzov, V. B. (2000). What will the teacher be in the era of virtual education? (Model of a teacher - tutor). Quality Education: Problems and Solutions: scientific seminar: abstracts. Novosibirsk, pp. 107- 114.

4- Kazanskaya, O.V. \& Nikitina, N.Sh. (2001). Teacher training in the field of distance learning technologies. Training for the open and distance education system. Tomsk: Publishing house of Tomsk State University, $146 \mathrm{p}$.

5- Liyanagunawardena, T.R., Adams, A.A., Rassool, N., Williams, S.A. (2014). Blended learning in distance education: Sri Lankan perspective. International Journal of Education and Development using Information and Communication Technology, Vol. 10, Issue 1, pp. 55-69.

6- Virgil, E. \& Varvel, J. (2007). Master online teacher competencies. Online Journal of Distance Learning Administration, Vol. 10(1), 1-41.

7- Akhmatova, D.B. \& Gurje, L.I. (2011). High school teacher and innovative technology. Higher Education in Russia, Vol. 4, pp. 138144.

8- Khursheed, B. (2001). Students and Tutors. Oxford: Oxford University Press, 218 p.

9- Rowland, S. (2000). The Encouraging University teacher. Buckingham: Open University Press, 246 p.

10- Moiseyeva, M. V. (2001). Preparation of Tutors in the area of new teaching technologies for distance learning system. Quality of remote education: concepts, problems. Zhukovskiy: MIM LINK, pp. 4245.

11- Gromova, T. (2011). Theory and technology of teachers preparation for work in distance learning (Doctoral dissertation). Tolyatti State University, Tolyatti, Samarskaya region, RF, $383 \mathrm{p}$.

12- Kustov, Y.A., V. A. Gusev. (2006). 10 lectures on the systems approach in vocational education. Samara-Togliatti, $90 \mathrm{p}$.

13- Bezrukova, V.S. (1990). Education: a Textbook for engineering and pedagogical specialties. Yekaterinburg: Sverdlovsk engineering-pedagogical Institute, $122 \mathrm{p}$.

14- Belousov, A.I. \& Gromova, T.V. (2011). Determining the readiness of the of high school teacher to distance education in the context of modernization of the education system. Vestnik of Samara University, Vol. 23 (27), pp. 287-295. 
15- Lerner, I. Y. (1981). Didactic bases of teaching methods. Moscow: Pedagogy, 186 p.

16- Lewis, Peter A., Tutticci, Naomi F., Douglas, Clint, Gray, Genevieve, Osborne, Yvonne, Evans, Katie, Nielson, Catherine M. (2016). Flexible learning: Evaluation of an international distance education program designed to build the learning and teaching capacity of nurse academics in a developing country. Original Research Article Nurse Education in Practice, Vol. 21, 59-65.

17- Gluhov, G.V., Gromova, T. V. (2016). Functional Components and Roles of the University Teacher in Distance Education. International Review of Management and Marketing. (S5). 235-242. Available at http: www.econjournals.com.

18- Atayan, Z.Sh. (2001). Technology of work of university teachers in LMS of MIM LINK. Quality Assurance System in Distance Education, Vol. 1. Zhukovsky: MIM LINK, pp.63-69.

19- Gavrilova, E.L. \& Sergeyeva T.A. (2001). Direct interaction of the teacher with the students in open distance education. Quality Assurance System in Distance Education. Zhukovsky: MIM LINK, Vol. 3, pp. 86-97.

20- Tuninga, R. (1995). The Supply and Demand of Distance Education in Russia. The World Bank, Bureau Cross, $110 \mathrm{p}$.

21- Kraineva, R. K. (2009). The System of management of educational services using distance technologies. (Abstract of candidate dissertation). Samara: Samara state university of economics, $22 \mathrm{p}$.

22- Khutorskoy, A. V. (2001). Scientificpedagogical preconditions of distance pedagogics. Open Education, Vol. 2, 30-35. 